
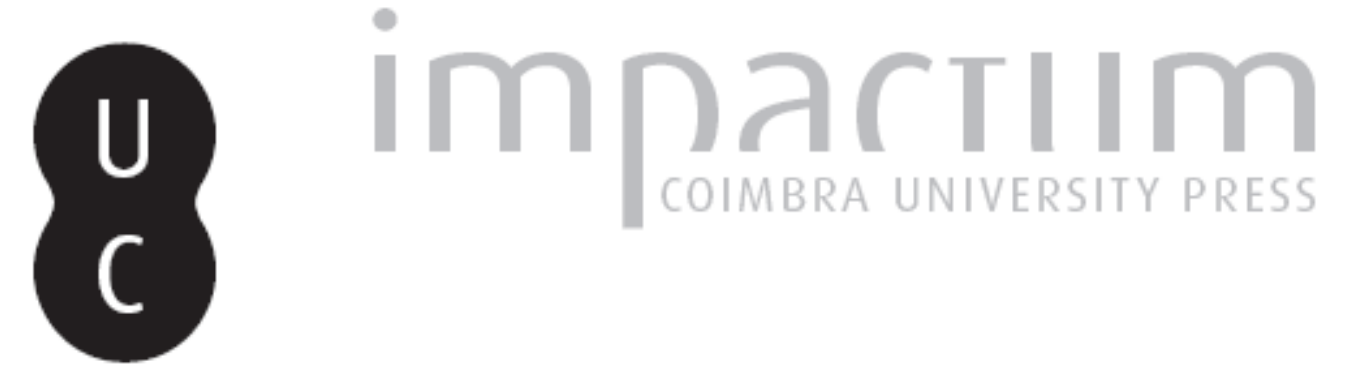

\title{
Aqueduto e barragem romanos do bairro Rio de Clérigos: (Alcácer do Sal)
}

Autor(es): $\quad$ Faria, João Carlos; Ferreira, Marisol A.

Publicado por: Imprensa da Universidade de Coimbra

URL persistente:

URI:http://hdl.handle.net/10316.2/45548

DOI:

DOI:https://dx.doi.org/10.14195/1647-8657_29_6

Accessed : $\quad$ 26-Apr-2023 04:40:59

A navegação consulta e descarregamento dos títulos inseridos nas Bibliotecas Digitais UC Digitalis, UC Pombalina e UC Impactum, pressupõem a aceitação plena e sem reservas dos Termos e Condições de Uso destas Bibliotecas Digitais, disponíveis em https://digitalis.uc.pt/pt-pt/termos.

Conforme exposto nos referidos Termos e Condições de Uso, o descarregamento de títulos de acesso restrito requer uma licença válida de autorização devendo o utilizador aceder ao(s) documento(s) a partir de um endereço de IP da instituição detentora da supramencionada licença.

Ao utilizador é apenas permitido o descarregamento para uso pessoal, pelo que o emprego do(s) título(s) descarregado(s) para outro fim, designadamente comercial, carece de autorização do respetivo autor ou editor da obra.

Na medida em que todas as obras da UC Digitalis se encontram protegidas pelo Código do Direito de Autor e Direitos Conexos e demais legislação aplicável, toda a cópia, parcial ou total, deste documento, nos casos em que é legalmente admitida, deverá conter ou fazer-se acompanhar por este aviso.

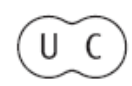


FACULDADE DE LETRAS

INSTITUTO DE ARQUEOLOGIA

CONIMBRIGA

VOLUME XXIX

UNIVERSIDADE DE COIMBRA

1990 
JOÃo CARLOS FARIA

Arqueólogo. Director do Museu Municipal de Alcácer do Sal.

MARISOL A. FERREIRA

Arqueóloga. Técnica responsável pelo sector do património cultural da Câmara Municipal de Grândola.

AQUEDUTO E BARRAGEM ROMANOS

DO BAIRRO RIO DE CLÉRIGOS (ALCÁCER DO SAL)

«Conimbriga», XXIX, 1990, 103-106

RESUMO: Dá-se sumária notícia da descoberta de mais 44 metros dum aqueduto romano já referenciado, que se abastecia numa barragem de aterro, a segunda até agora reconhecida no Sul de Portugal.

RÉSUMÉ: Notice de la découverte, à Salacia, de $44 \mathrm{~m}$ en plus d'un aqueduc romain déjà connu. L'eau provenait d'un barrage de remblai, le second de ce genre jusqu'à présent identifié au Sud du Portugal. 
(Página deixada propositadamente em branco) 


\section{AQUEDUTO E BARRAGEM ROMANOS DO BAIRRO RIO DE CLÉRIGOS (ALCÁCER DO SAL)}

$\mathrm{O}$ aqueduto romano do Bairro Rio de Clérigos situa-se a $1 \mathrm{~km}$ a $\mathrm{NE}$ da vila de Alcácer do Sal, tendo como coordenadas quilométricas Gauss as seguintes: $\mathrm{M}=167,8 \mathrm{P}=156,5$.

Este monumento foi identificado pelos signatários que dele já deram uma breve notícia ${ }^{1}$ ).

Durante o ano de 1990, fomos solicitados a intervir no local, pois, por motivo de obras de terraplanagem, haviam sido colocados a descoberto 44 metros do aqueduto, a acrescentar aos outros 38 metros já referenciados.

Tratava-se, no fundo, de executar trabalhos de limpeza, fotografia e desenho arqueológico, a fim de o registar convenientemente, já que o troço do monumento ora descoberto se situa numa zona de expansão do bairro e não poderá, por esse facto, comprometer as construções urbanísticas para ali previstas.

Os trabalhos superiores autorizados revelaram um aqueduto constituído por um simples canal assente num muro em opus incertum, cujas paredes externas foram cobertas de argamassa, de que se notam alguns vestígios.

Os blocos deste muro são, na sua maioria, de calcário miocènico da região, encontrando-se igualmente presente o xisto e, em menor quantidade, a brecha da Arrábida.

O canal possui uma largura interna de 0,32 metros apresentando as paredes revestidas de opus signinum. Teria provavelmente uma cobertura do mesmo tipo de opus, pois durante a limpeza do seu interior encontrámos abundantes fragmentos de tijolo britado.

Todo o conjunto assenta directamente em terrenos arenosos do miocènico onde foi aberta uma simples vala para a sua implantação.

(!) João C. Lázaro Faria, Marisol A. Ferreira, Estações inéditas da época romana do concelho de Alcácer do Sal, "Conimbriga", XXV, 1986, p. 46.

Conimbriga, 29 (1990), 103-106 
Este aqueduto teria como finalidade abastecer de água a antiga Salacia Imperatoria, situada inclusivamente a uma cota mais baixa.

A origem deste aqueduto situava-se numa barragem romana de planta rectilínea, constituída por aterro de material terroso.

Trata-se de uma estrutura inédita, onde a antiga albufeira se encontra bem individualizada, sendo perfeitamente perceptível através de fotografia aérea $\left({ }^{2}\right)$. Esta obra assemelha-se bastante à barragem do Monte Novo do Castelinho (Almodôvar) $\left(^{3}\right)$.

Até ao presente momento, a nossa barragem e a de Monte Novo constituem os dois únicos exemplares romanos de barragens exclusivamente de aterro no Sul de Portugal. Contudo, a norte do Tejo, foram reconhecidas três importantes barragens de aterro: Rochoso (Idanha-a-Nova), Idanha-a-Velha (Idanha-a-Nova) e Lameira (Vila Velha de Ródão) ( ${ }^{4}$ ).

Por certo, é provável que tivesse uma dupla finalidade, ou seja, por um lado destinar-se a abastecer a cidade romana de Salacia, por outro, permitir a rega dos terrenos ainda hoje férteis do vale que se situa imediatamente a juzante dela e, portanto, a uma cota inferior.

De notar que, para além desta, as únicas barragens em que é francamente evidente a relação com um canal de abastecimento a um habitat são a de Vale Tesnado (Loulé) e a de Comenda (Setúbal) ${ }^{(5)}$.

Muito provavelmente, a água desta barragem proviria, para além das chuvas, de uma captação de nascente, de que poderá ser prova disso a existência, a montante da barragem, de um poço cuja água, dizem, "nunca se esgota".

(2) Os nossos mais sinceros agradecimentos ao Dr. A. M. Dias Diogo por nos ter amavelmente cedido a presente fotografia.

(3) António Carvalho Quintela, João Luís Cardoso, João Manuel Mascarenhas, Aproveitamentos Hidráulicos Romanos a Sul do Tejo, Lisboa, 1986, p. 92-93.

(4) Ob. cit. 1986 p. 52.

(5) Ob. cit. 1986 p. 52 


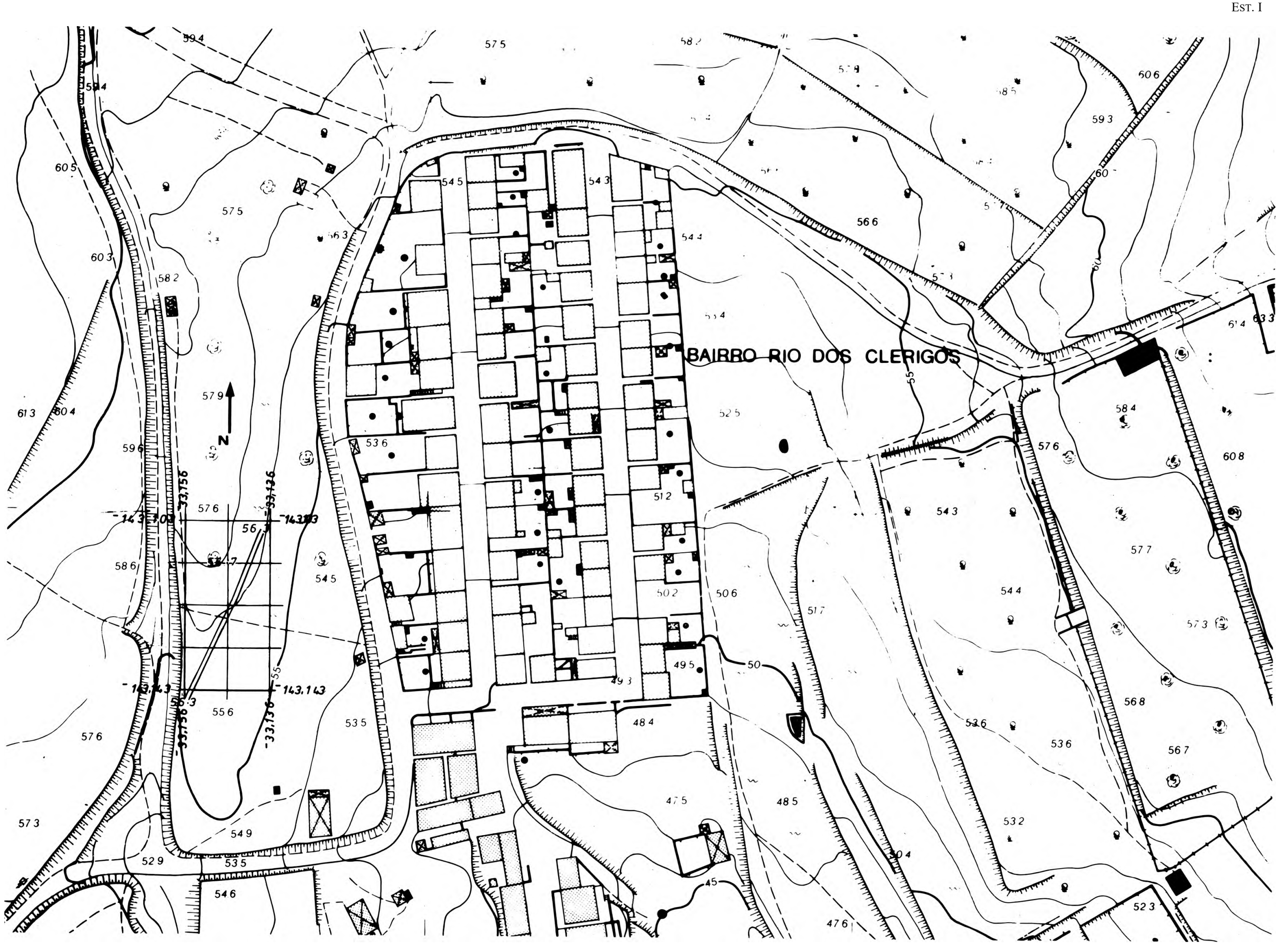


(Página deixada propositadamente em branco) 
EST. II

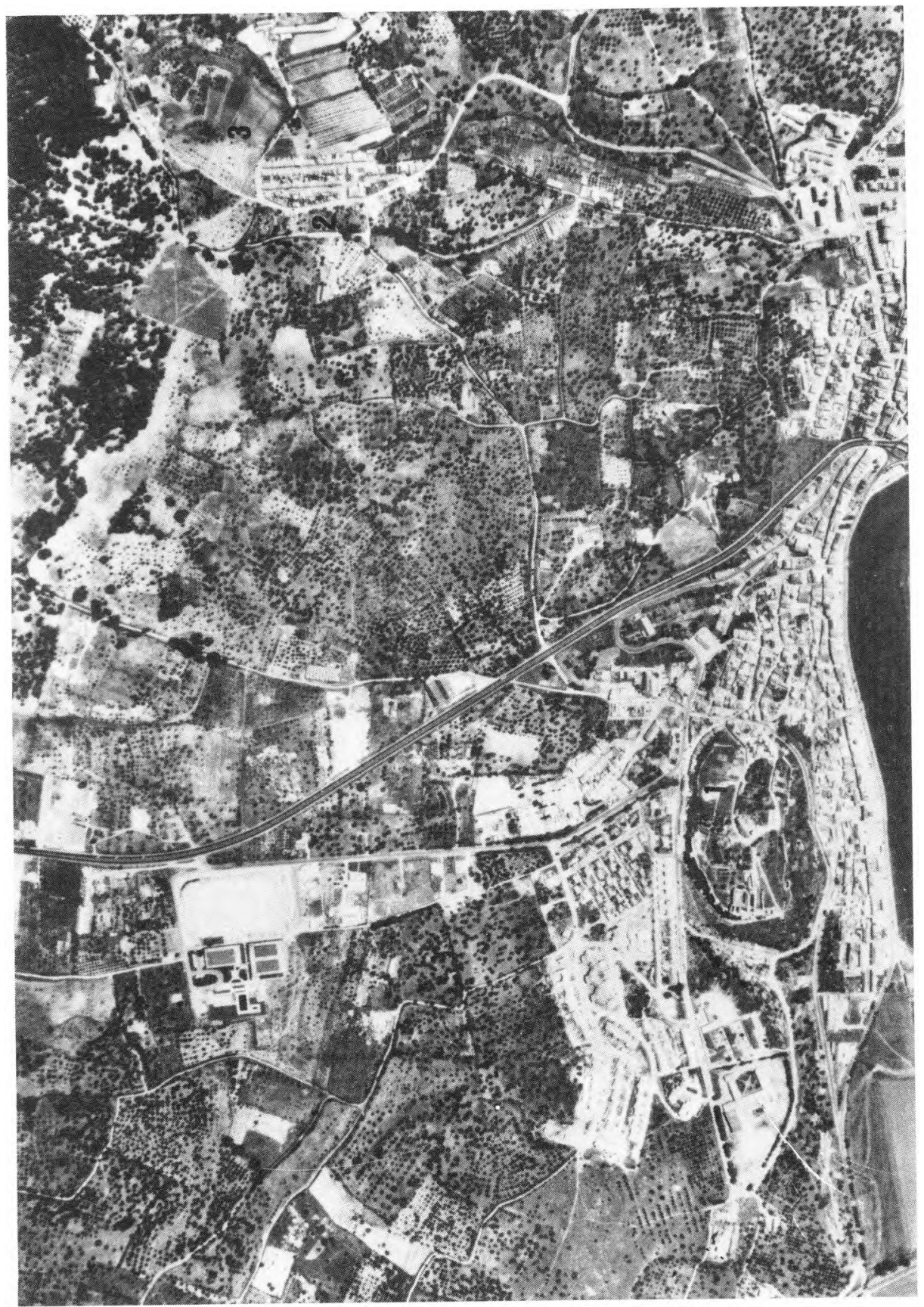




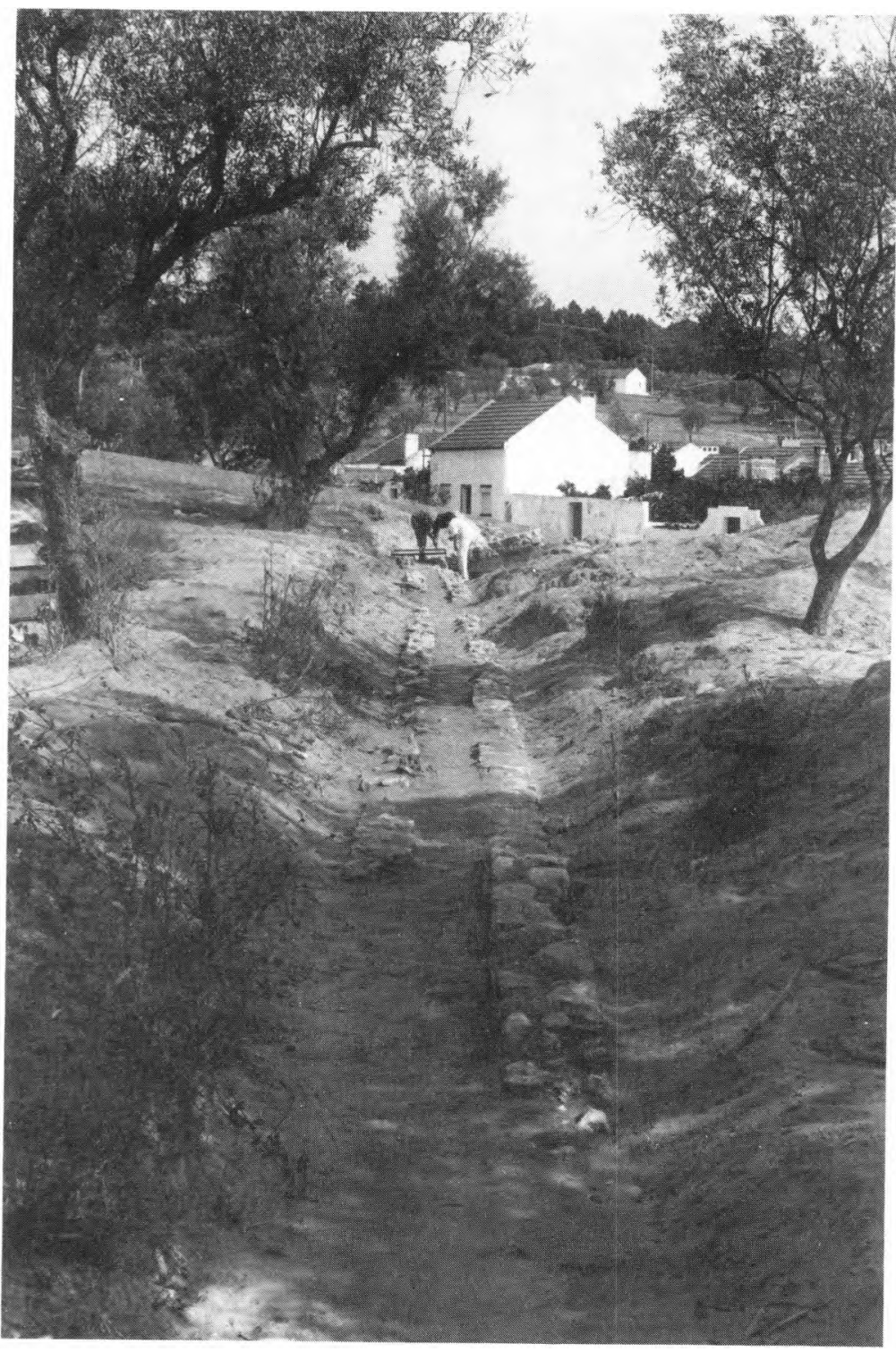

